\title{
Region-Specific Effects of Nicotine on Brain Activity: A Pharmacological MRI Study in the Drug-Naïve Rat
}

\author{
Alessandro Gozzi*,', Adam Schwarz', Torsten Reese', Simone Bertani ${ }^{2}$, Valerio Crestan ${ }^{2}$ and \\ Angelo Bifone' \\ 'Department of Neuroimaging, Centre of Excellence for Drug Discovery, Psychiatry, GlaxoSmithKline Medicines Research Centre, Verona, Italy; \\ ${ }^{2}$ Laboratory Animal Sciences, Centre of Excellence for Drug Discovery, Psychiatry, GlaxoSmithKline Medicines Research Centre, Verona, Italy
}

\begin{abstract}
We have applied pharmacological magnetic resonance imaging (phMRI) methods to map the functional response to nicotine in drugnaïve rats. Nicotine $(0.35 \mathrm{mg} / \mathrm{kg}$ intravenous (i.v.)) increased relative cerebral blood volume (rCBV) in cortical (including medial prefrontal, cingulate orbitofrontal, insular) and subcortical (including amygdala and dorsomedial hippocampus) structures. The pharmacological specificity of the effect was demonstrated by acute pretreatment with the nicotinic acetylcholine receptor (nAChR) ionchannel-blocking agent mecamylamine, which suppressed the rCBV response to nicotine. Control experiments with norepinephrine, a potent non-brain-penetrant vasopressor, at a dose that mimics the cardiovascular response induced by nicotine were performed to assess the potential confounding effects of peripheral blood pressure changes induced by nicotine. In an attempt to highlight the relative contribution of different $n A C h R$ subtypes to the observed activation pattern of nicotine, we also investigated the central phMRI response to an acute challenge with (R)-N-(I-azabicyclo[2.2.2]oct-3-yl)(5-(2-pyridyl)thiophene-2-carboxamide) (cpdA, at 5, I0, 20, and 30 mg/kg i.v.) and 5-iodo-A-85380 (5IA, $5 \mathrm{mg} / \mathrm{kg}$ i.v.). CpdA is a selective agonist at homomeric $\alpha 7 \mathrm{nAChRs}$, while $5 \mathrm{IA}$ features high in vivo affinity for the $\alpha 4 \beta 2$ * and other less-abundant $\beta 2$-containing nicotinic receptors. CpdA did not produce significant rCBV changes at any of the doses tested, whereas 5IA induced a pattern of activation very similar to that induced by nicotine. The lack of phMRI response to cpdA together with the high spatial overlap between the activation profile of nicotine and 5IA, suggest that the acute functional response to nicotine in drug-naïve rats is mediated by $\beta 2$-containing $\mathrm{nAChR}$ isoforms, presumably belonging to the $\alpha 4 \beta 2 *$ subtype.

Neuropsychopharmacology (2006) 31, 1690-1703. doi:I0. I038/sj.npp. I 300955; published online 16 November 2005
\end{abstract}

Keywords: nicotine; $\mathrm{fMRl}$; rat; CBV; A-85380; alpha 7

\section{INTRODUCTION}

Nicotine, the major addictive component of tobacco, is one of the most widely used psycho-stimulating drugs (Corrigall, 1991). Acute exposure to nicotine enhances cognitive functions such as attention, learning, and memory in both animals and humans (Levin and Simon, 1998; Rezvani and Levin, 2001; Levin and Rezvani, 2002), while repeated exposure to nicotine via tobacco smoke can lead to longlasting changes in the biochemistry of the brain and concomitant changes in responsiveness in a variety of physiological measures (Laviolette and Van der Kooy, 2004). Nicotine exerts its effects on the CNS by interacting

* Correspondence: Dr A Gozzi, Department of Neuroimaging, Centre of Excellence for Drug Discovery, Psychiatry, GlaxoSmithKline Medicines Research Centre, Via Fleming 4, 37 I 35 Verona, Italy,

Tel: + 390 458219233, Fax: + 390458218073 ,

E-mail: alessandro.2.gozzi@gsk.com

Received 17 June 2005; revised 10 August 2005; accepted 19 September 2005

Online publication: 6 October 2005 at http://www.acnp.org/citations/ Npp I00605050394/default.pdf with nicotinic acetylcholine receptors (nAChRs). nAChRs are ligand-gated ion channels existing in multiple pentameric subunit combinations (for a review, see McGehee and Role, 1995). Nine of the known alpha subunits $(\alpha 2-\alpha 10)$ and three of the known beta subunits $(\beta 2-\beta 4)$ have been found in the central and peripheral nervous systems of animals (Itier and Bertrand, 2001). Despite the potential for wide diversity, the most abundant nicotinic receptors in the mammalian brain are the homomeric $\alpha 7$ and the heteromeric $\alpha 4 \beta 2^{*}$ receptors (The designation ' $\alpha 4 \beta 2^{*}$ ' means that these receptors contain $\alpha 4$ and $\beta 2$ subunits and that other subunits (eg, $\alpha 5$ or $\alpha 6$ ) may be incorporated in this pentameric complex (Lukas et al, 1999)). (Flores et al, 1992; Holladay et al, 1997; Paterson and Nordberg, 2000). Nicotine acts in vitro as a prototypic agonist for nAChRs, with very high affinity for the $\alpha 4 \beta 2^{\star}$ subtype, and lower but significant affinity for several other nAChR subclasses, including the $\alpha 7, \alpha 3^{*}$ and $\alpha 6^{*}$ (Gotti et al, 1997; Kuryatov et al, 2000; Wonnacott and Sharples, 2001; Romanelli and Gualtieri, 2003). The high affinity of nicotine for the $\alpha 4 \beta 2^{*}$ nAChR subtype and its relative abundance in the brain make this receptor one of the predominant targets 
mediating the psychoactive properties of nicotine. However, recent evidence suggests that other subtypes of nAChRs might also modulate aspects of the addictive, reinforcing, and cognitive properties of nicotine (Le Novere et al, 1999; Schilstrom et al, 2003; Laviolette and Van der Kooy, 2004; Wonnacott et al, 2005). Until recently, lack of selective ligands able to discriminate between the different subtypes of nAChRs has hampered the characterization of functional differences between these receptors in vivo. Moreover, nicotine's pharmacological effects are further complicated by the fact that it may either stimulate or desensitize nAChRs and consequently the stimulatory or inhibitory nicotinic responses converge to produce varying effects in different brain structures (Dani and Heinemann, 1996; Chiodini et al, 1999). As a consequence, little is known of the relative contribution of the different $\mathrm{nAChR}$ subtypes to the pharmacological and behavioral effects of nicotine at a system level.

Brain-mapping methods permit to locate and quantify the central action of nicotine and abused substances in laboratory animals. 2-Deoxyglucose utilization studies and cerebral blood flow (CBF) mapping with iodo-antipyrene following acute or chronic nicotine administration have evidenced significant signal changes in several striatal and limbic structures (Grunwald et al, 1987, 1991; London et al, 1988a, 1990). Analogously, Fos protein immunohistochemistry has shown elevated signal in restricted brain regions, including target areas of the limbic system, areas related to the optic system, as well as several dopamineinnervated structures (Ren and Sagar, 1992; Matta et al, 1993; Pang et al, 1993; Kiba and Jayaraman, 1994; Nisell et al, 1997; Mathieu-Kia et al, 1998; Schilstrom et al, 2000; Seppa et al, 2001). Although such autoradiography and immunohistochemical techniques have a high spatial resolution, the ex-vivo nature of the approach restricts their use to animal studies and obviously limits temporal resolution to a single point per animal or an average change in activity integrated over a long time period. Recent neuroimaging techniques such as pharmacological magnetic resonance imaging (phMRI) have gained increasing use in animal experimentation as high spatial and temporal resolution images of the brain are attainable noninvasively from rodent brains in vivo (Jenkins et al, 2003; Schwarz et al, 2004a, b; Gozzi et al, 2005b). Moreover, phMRI may be employed to link mechanistic studies of drug action in preclinical animal models with the clinical investigation of nicotine's functional activity.

In this study, we employed a drug-naïve rat model to investigate the anatomical and temporal patterns of brain activation induced by nicotine using phMRI methods. Potential confounds arising from peripheral blood pressure changes were assessed performing a control experiment with norepinephrine, a potent non-brain-penetrant vasopressor (Oldendorf, 1971), at a dose that mimics the cardiovascular response induced by nicotine. The nAChR ion-channel-blocking agent mecamylamine (Papke et al, 2001) was used to prove the pharmacological specificity of the functional changes. In an attempt to highlight the relative contribution of different $\mathrm{nAChR}$ subtypes to the observed activation pattern of nicotine, we also investigated the central phMRI response to an acute challenge with two selective nAChR agonists: $(R)-N-(1$-azabicyclo[2.2.2]oct-3- yl)(5-(2-pyridyl)thiophene-2-carboxamide) (cpdA) and 5iodo-A-85380 (3-[(2S)-2-azetidinylmethoxy]-5-iodopyridine) (5IA). CpdA is a potent and selective $\alpha_{7} \mathrm{nAChR}$ agonist that crosses the blood-brain barrier (O'Neill et al, 2002; Bunnelle and Decker, 2003; Cilia et al, 2005). 5IA is a compound that features high affinity towards $\beta 2^{*} v s \alpha 7$ and other nAChR subtypes in vitro (ratio of $K_{\mathrm{i}(\alpha 7)}$ ) $K_{\mathrm{i}(\alpha 4 \beta 2)} \sim 25000$ (Mukhin et al, 2000; Mogg et al, 2004)), and has been shown to interact with agonist binding sites on nAChRs in the brain (Vaupel et al, 1998; 2005). A preliminary account of this work has been presented (Gozzi et al, 2005a, c).

\section{MATERIALS AND METHODS}

\section{Animal Preparation}

All experiments were carried out in accordance with Italian regulations governing animal welfare and protection. Protocols were also reviewed and consented to by a local animal care committee, in accordance with the guidelines of the Principles of Laboratory Animal Care (NIH publication 86-23, revised 1985). These studies were performed on male Sprague-Dawley rats (250-350 g) (Charles River, Como, Italy). Animals had free access to standard rat chow and tap water and were housed in groups of five in solid bottom cages with sawdust litter. Room temperature $\left(20-22^{\circ} \mathrm{C}\right)$, relative humidity (45-65\%), and dark-light cycles ( $12 \mathrm{~h}$ each, lights on at $06: 00 \mathrm{~h}$ ) were automatically controlled. After arrival, rats were allowed to acclimatize for at least 5 days.

On the day of MR experiment, the rats were anesthetized with $3 \%$ halothane (Wyeth, Italy) in a $30: 70 \% \quad \mathrm{O}_{2}: \mathrm{N}_{2}$ gas mixture, tracheotomized, and artificially ventilated with a mechanical respirator (Inspira, Oxford, UK). Upon tracheotomy and throughout surgery, the anesthetic level was maintained at $1.5 \%$. The left femoral artery and vein were cannulated and animal paralysis was achieved by a $0.25 \mathrm{mg} /$ $\mathrm{kg}$ intravenous (i.v.) bolus of D-tubocurarine (SigmaAldrich, Milano, Italy), followed by a continuous infusion of $0.25 \mathrm{mg} / \mathrm{kg} / \mathrm{h}$ (in heparinized saline $25 \mathrm{IU} / \mathrm{ml}$ ) through the artery. The rats employed in studies 2 and 3 (see below) were also provided with an intraperitoneal PE50 cannula. All wounds were infiltrated with $1 \%$ lidocaine before incision. At the end of surgery rats were secured into a customized stereotactic holder (Bruker, Ettlingen, Germany). In order to monitor arterial blood gases, $200 \mu \mathrm{l}$ blood samples were withdrawn from the arterial catheter both before positioning the animal in the magnet and at the conclusion of the experiment, and analyzed for partial pressure of oxygen, carbon dioxide, and $\mathrm{pH}$ (AVL, Roswell, GA, USA). Following the former measurement, ventilation parameters were adjusted in order to keep the arterial blood gas values within physiological range $\left(29<p \mathrm{CO}_{2}\right.$ $<50 \mathrm{mmHg} ; p \mathrm{O}_{2}>100 \mathrm{mmHg}$ ). Student's $t$-test analysis of blood gas data (corrected for multiple comparisons using Hochberg's procedure) did not evidence systematic differences between $p \mathrm{CO}_{2}$ or $p \mathrm{O}_{2}$ values pre- and post-MRI, or between groups. Arterial blood pressure was monitored continually throughout the MRI experiment. The heart rate was calculated from arterial pressure pulses by the physiological data acquisition software (Biopac systems 
Inc., Goweta, CA, USA). An MR-compatible thermocouple probe was used to check rectal temperature at the beginning and at the end of the experiment. During the image acquisition, the maintenance level of anesthesia was set to $0.8 \%$.

As D-tubocurarine is a non-brain-penetrant competitive nAChR antagonist (Alyautdin et al, 1998), preliminary experiments in curarized $v$ s freely breathing animals were carried out to rule out unfavorable crossinteractions between nicotine and the neuromuscular blocker. These studies did not evidence detectable interaction between the two compounds, as the cardiovascular response to nicotine was similar in the two groups, and the paralyzing effect of D-tubocurarine was not affected by the administration of the nicotine bolus.

\section{Experiments and Compounds}

Six studies were performed in order to evaluate the central phMRI response to nicotine and its pharmacological mechanism:

(1) Acute i.v. challenge of nicotine ((-)-nicotine hydrogen tartrate, Sigma-Aldrich, Italy) at two doses $(0.35 \mathrm{mg} / \mathrm{kg}$ nicotine free-base (This dose is equivalent to $1 \mathrm{mg} / \mathrm{kg}$ of the salt form) $(n=9)$ or $0.1 \mathrm{mg} / \mathrm{kg}(n=7))$ vs vehicle (saline $(n=9))$.

(2) Acute i.p. challenge with mecamylamine (mecamylamine hydrochloride, Sigma-Aldrich, Italy, $0.35 \mathrm{mg} / \mathrm{kg}$ $(n=6))$ vs vehicle (saline $(n=6))$.

(3) Acute pretreatment with either mecamylamine $(1 \mathrm{mg} / \mathrm{kg}$ i.p. $(n=7))$ or vehicle (saline i.p. $(n=9)) 30 \mathrm{~min}$ prior to an i.v. nicotine challenge $(0.35 \mathrm{mg} / \mathrm{kg})$. A group of four rats pretreated and challenged with vehicle was used as negative control.

(4) Acute i.v. challenge with cpdA (5 $(n=2), 10(n=4), 20$ $(n=5)$ and $30(n=4) \mathrm{mg} / \mathrm{kg})$ vs vehicle (saline $(n=5))$.

(5) Acute i.v. challenge with 5IA (Tocris Cookson Ltd, UK, $5 \mathrm{mg} / \mathrm{kg}$ i.v. $(n=6))$ vs vehicle (saline $(n=5))$.

(6) Acute i.v. challenge with norepinephrine (SigmaAldrich, Italy, $0.5 \mu \mathrm{g} / \mathrm{kg}$, i.v. $(n=4))$. This experiment was performed in order to assess potential confounds arising from peripheral blood pressure changes elicited by nicotine. Norepinephrine is a potent non-brainpenetrant vasopressor (Tuor et al, 2002), and the dose of $0.5 \mu \mathrm{g} / \mathrm{kg}$ was selected so as to mimic the cardiovascular response to nicotine.

To enhance the solubility of cpdA in saline, the medium was slightly acidified with a few microliters of $\mathrm{HCl} 1 \mathrm{~N}$, and subsequently corrected to neutral $\mathrm{pH}(7 \pm 1)$ with $\mathrm{NaOH}$ $1 \mathrm{M}$. Nicotine, mecamylamine, 5IA, and norepinephrine were dissolved in normal saline. All the compounds were administered as $1 \mathrm{ml}$ bolus infusion, followed by a $400 \mu \mathrm{l}$ flush of saline, at a rate of $1 \mathrm{ml} / \mathrm{min}$. The doses of nicotine were selected based on the results of a functional $c$-fos study (Mathieu-Kia et al, 1998). Mecamylamine, at the dose used in this study, has been previously shown to effectively antagonize both the functional and behavioral changes induced by nicotine (Reavill and Stolerman, 1990; Seppa et al, 2001). The dose of 5IA was empirically selected following a preliminary study in which lower quantities $(0.3$,
1 and $3 \mathrm{mg} / \mathrm{kg}$ ) were also evaluated. Detectable signal changes were observed at 1 and $3 \mathrm{mg} / \mathrm{kg}$, and at $5 \mathrm{mg} / \mathrm{kg}$ the changes were consistent and reproducible enough to yield robust group activation maps. All the doses of cpdA used in this study are behaviorally effective in the rat (Wadsworth et al, 2005; Cilia et al, 2005). At the end of the experiment rats were euthanized with an overdose of anesthetic agent.

\section{Magnetic Resonance Imaging}

The MRI data were acquired using a Bruker Avance $4.7 \mathrm{~T}$ system. The animals were positioned prone in the manufacturer's holding support and a 'Rat Brain' curved quadrature receive coil (Bruker, Ettlingen, Germany) was mounted on top of the animal skull and fixed to the animal holder. The animal holder was then fitted into a $72 \mathrm{~mm}$ birdcage resonator (Bruker, Ettlingen, Germany), which was used for radiofrequency transmit only. Both coils are standard components provided by the manufacturer.

For each MRI experiment, high-resolution $\mathrm{T}_{2}$-weighted anatomical images were acquired using the RARE sequence with RARE factor 32 , matrix $256 \times 256$, FOV $40 \mathrm{~mm}$, slice thickness $1 \mathrm{~mm}, 32$ contiguous slices. These were acquired in the coronal plane, centered $10 \mathrm{~mm}$ caudal from the posterior edge of the olfactory bulb. The phMRI time series images were acquired using the same $\mathrm{T}_{2}$-weighted RARE sequence with the same FOV and geometrical center, but a smaller matrix size of $128 \times 128$ and eight contiguous 2 mm-thick coronal slices. The rostro-caudal coverage of the time series acquisition was approximately from $z_{\text {bregma }}+$ $4 \mathrm{~mm}$ (anterior edge of slice 1 ) to $z_{\text {bregma }}-12 \mathrm{~mm}$ (posterior edge of slice 8$)$. The time parameters were $\mathrm{TE}_{\text {eff }}=110 \mathrm{~ms}$ and $\mathrm{TR}=2700 \mathrm{~ms}$, with four or eight inline averages, yielding a temporal resolution $\delta t$ of 40 or $80 \mathrm{~s}$, with 64 or 90 sequential time frames (depending on the study). The use of $\mathrm{T}_{2}$-weighted images for the time-series acquisition minimizes sensitivity both to large blood vessels and inhomogeneities of the static magnetic field (Ogawa et al, 1993; Weisskoff et al, 1994; Reese et al, 2000), and also ensured that the geometry of the time-series images matched the anatomical reference images, facilitating subsequent image analysis.

A $2.67 \mathrm{ml} / \mathrm{kg}$ dose of Endorem blood pool contrast agent (Guerbet, France) was administered i.v. following five reference image frames, to sensitize the acquisition to changes in CBV. Prior to the injection of any pharmacological agent, an equilibration period of $15 \mathrm{~min}$ was allowed. The MRI data were acquired over a period of $25-45 \mathrm{~min}$ (depending on the study) following the administration of the pharmacological challenge.

\section{Data Analysis}

The phMRI time-series data for each experiment were analyzed on both an image and region of interest (ROI) basis within the framework of the general linear model (GLM) using AFNI v.2.23 (Cox and Hyde, 1997).

For each study, the anatomical images from each subject were first spatially coregistered together by rigid body alignment to a template animal chosen from within the study. The transformation parameters for each subject were 
subsequently applied to the respective time-series data. The use of the paralyzing agent ensured that no motion-related effects were present in the time series. Data from all animals were checked for motion following acquisition by subtraction of image frames at the beginning and end of the time series, and at appropriate intermediate points (eg, before and after injection). No motion artifacts were detected.

Signal intensity changes in the time series were then converted into fractional relative cerebral blood volume (rCBV) changes on a pixel-wise basis using the transform (Mandeville et al, 1998)

$$
r C B V(t)=\frac{\ln (S(t) / B(t))}{\ln \left(B(t) / S_{\mathrm{PRE}}\right)}
$$

where $S(t)$ is the measured signal intensity, $B(t)$ is the estimated background signal in the absence of transient functional stimuli, and $S_{\mathrm{PRE}}$ is the signal intensity prior to administration of the contrast agent. $B(t)$ was set equal to the mean signal intensity $B_{0}$ during a 3 -min period prior to compound injection. To quantify the response to the i.v. challenges, rCBV time series were calculated covering an $8 \mathrm{~min}$ preinjection baseline and $14 \mathrm{~min}$ post-injection (16 or 32 time points), normalized to a common injection time point within each study. This time window captured the relatively rapid phMRI signal changes observed following injection of the compounds investigated in this study.

For image-based analysis, the rCBV time series were smoothed by a $0.6 \mathrm{~mm}(\sim 2$ pixels) FWHM Gaussian kernel in order to increase robustness to small differences in brain shape for subsequent group analysis. The functional response was then quantified by a pixel-wise multiple linear regression. For the nicotine and 5IA experiments, in which a clear response was observed, the regressor of interest was determined from a time course clustering method, wavelet cluster analysis (Whitcher et al, 2005) applied at the group level. This approach identifies a temporal component reflecting a common post-injection response across all subjects, suitable for use as a signal model in the GLM analysis (Schwarz et al, 2005). For the analysis of the mecamylamine and cpdA challenges, no clear signal changes were observed and so a post-injection boxcar model was used in order to identify regions systematically implicated in the response. Constant and linear polynomial terms were also included in the design matrix as regressors of no interest, allowing for background changes such as the slow negative drift in the rCBV signal due to contrast agent washout (Schwarz et al, 2003). The fitted coefficients of the regressor of interest were then analyzed at the group level by pixel-wise unpaired $t$-tests between appropriate groups (eg, compound $v s$ vehicle) in a random-effects analysis. Statistical threshold of effect for group maps was determined using the Benjamini-Hochberg procedure (Genovese et al, 2002), with the threshold set at a false discovery rate of $1 \%(q=0.01)$.

RCBV time courses were extracted a posteriori for specific ROIs based on correspondence between the anatomical images and an anatomical atlas (Paxinos and Watson, 1998; see Figure 1 for ROI localization). From each ROI, the rCBV time course was extracted as the mean value within the ROI for each time point, for each animal. Quantification of the response and group comparisons within each ROI were performed using the same random effects GLM approach as outlined above.

Relative changes in mean arterial blood pressure (MABP) measures were compared between groups at each time point $(20 \mathrm{~s}$ interval) using the Student's $t$-test. The level of significance was adjusted for multiple comparisons using Hochberg's method.

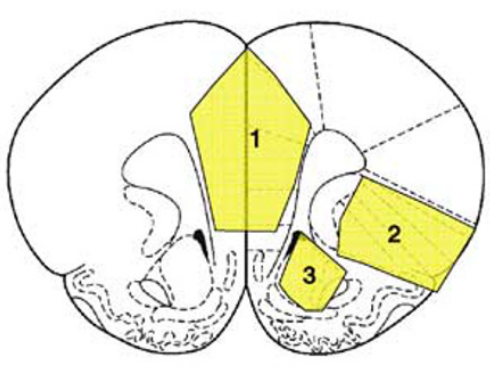

Bregma 2.70

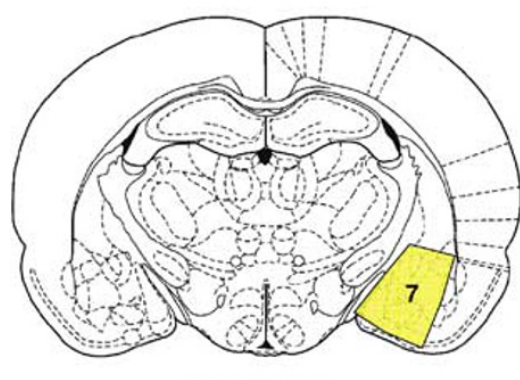

Bregma -2.80

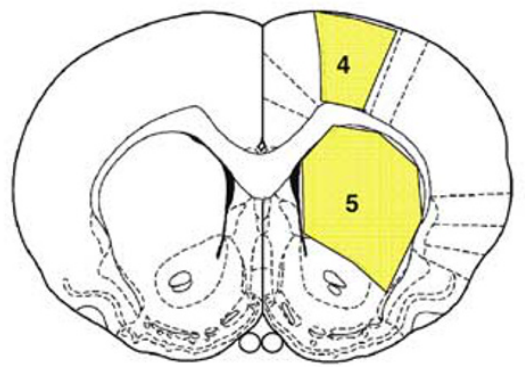

Bregma 1.20

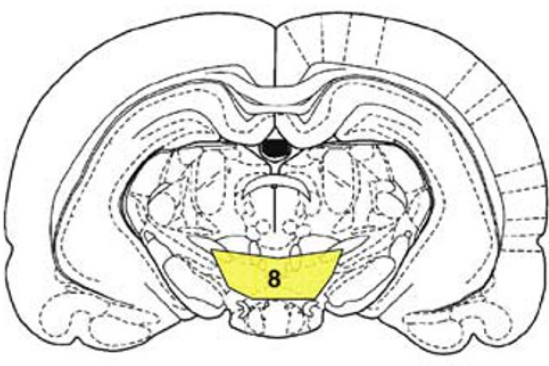

Bregma -4.80

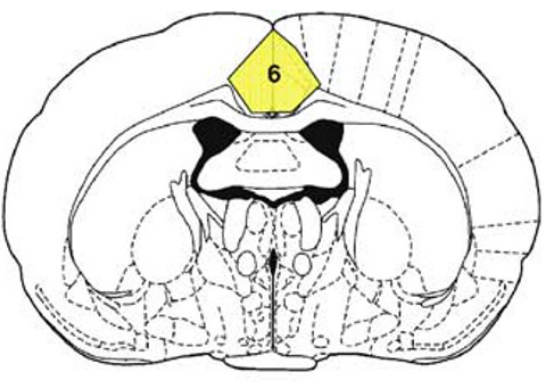

Bregma -0.92

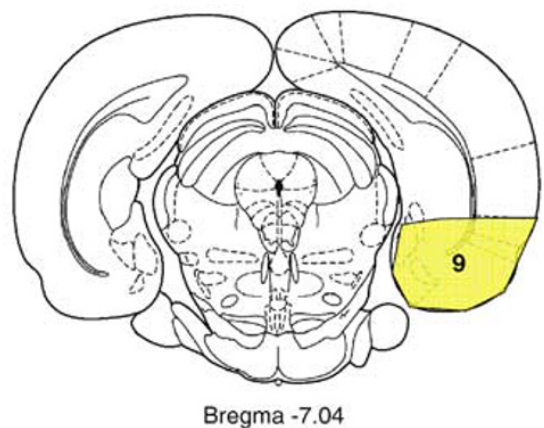

Figure I Coronal rat brain atlas diagrams from Paxinos and Watson (1998) corresponding to the middle of each 2 mm phMRI slice and indicating the ROls evaluated in this study ( 1 : nucleus accumbens, 2: orbital cortex, 3: mPFC, 4: primary motor cortex MI, 5: caudate putamen, 6: cingulate cortex, 7: amygdala, 8: lateral hypothalamus, 9: rhinal cortex). 


\section{RESULTS}

Acute nicotine injection at $0.35 \mathrm{mg} / \mathrm{kg}$ yielded increased rCBV in a distinct and reproducible pattern of activation. This response included the medial prefrontal cortex (mPFC) and cingulate cortex, with extension into the orbitofrontal, insular, piriform, and rhinal cortices (Figure 2). Activation of subcortical structures was also evident, with discrete regional increases in the amygdala, ventrocaudal hippocampal structures, and the anterior portion of the nucleus accumbens. At no time after nicotine infusion were any significant changes in CBV detected in any discernable portion of cerebellum, midbrain tegmentum, medulla, or pons. The lower dose of nicotine $(0.1 \mathrm{mg} / \mathrm{kg})$ produced a much weaker response that did not reach statistical significance in all the regions described above (Figure 4).

The time course profile of nicotine-induced activation was analyzed in (nine ROIs) selected a posteriori (see Figure 1 for ROI localization). Since no systematic difference in the profile and the extent of $\mathrm{rCBV}$ response between the two brain hemispheres was observed, the ROI analysis was limited to the right hemisphere only. All the regions examined except the caudate putamen, the somatosensory cortex, and the hypothalamus showed a rapid increase in $\mathrm{rCBV}$ peaking approximately $2 \mathrm{~min}$ after injection, followed by a gradual return toward preinjection baseline values (Figure 3 ). The strongest signal changes were seen in the mPFC $(+19.0 \pm 4.4 \%)$ and in the orbital cortex $(+13.9 \pm 4.5 \%)$. Despite the difference in the magnitude of the effect, the overall profile and duration of the response did not appear to be region-dependent.
Pretreatment with MEC ( $1 \mathrm{mg} / \mathrm{kg}$ i.p.) significantly attenuated the nicotine-induced $\mathrm{rCBV}$ increase in all activated regions (Figures 3 and 4). Pretreatment with vehicle (saline) did not affect the magnitude and spatial distribution of the nicotine response. MEC per se did not produce significant $\mathrm{rCBV}$ changes anywhere in the brain. Neither MEC nor vehicle affected the slope and magnitude of basal CBV values prior to nicotine injection.

Acute challenge with 5IA produced reproducible and region-specific positive $\mathrm{rCBV}$ changes in all the cortical and subcortical structures activated by nicotine (Figure 5). 5IA also produced positive activation in regions of the dorsomedial thalamus, and in the hypothalamic areas. The time profile of CBV in the activated structures was similar to the one observed with nicotine (Figure 6). At no time after 5IA infusion were any significant changes in CBV detected in any discernable portion of cerebellum, medulla, or pons.

CBV group maps of animals challenged with cpdA did not show significant $\mathrm{rCBV}$ changes at any of the doses tested (5, 10,20 , and $30 \mathrm{mg} / \mathrm{kg}$ i.v.) The temporal profiles of activation in ROIs also did not evidence significant activation in any of the nine regions analyzed (Figures 6 and 7).

I.v. administration of saline (vehicle) did not give rise to significant changes in peripheral blood pressure. Nicotine $(0.35 \mathrm{mg} / \mathrm{kg})$ induced a transient increase in arterial blood pressure, peaking approximately $90 \mathrm{~s}$ after the injection $(+$ $27.1 \pm 9.8 \%, p<0.05$ at peak compared to vehicle (Figure 8$)$ ) and returning to preinjection baseline levels within $4 \mathrm{~min}$ form the injection. No correlation between response amplitude and absolute or relative MABP changes was found in any of the ROIs examined. The lower dose of

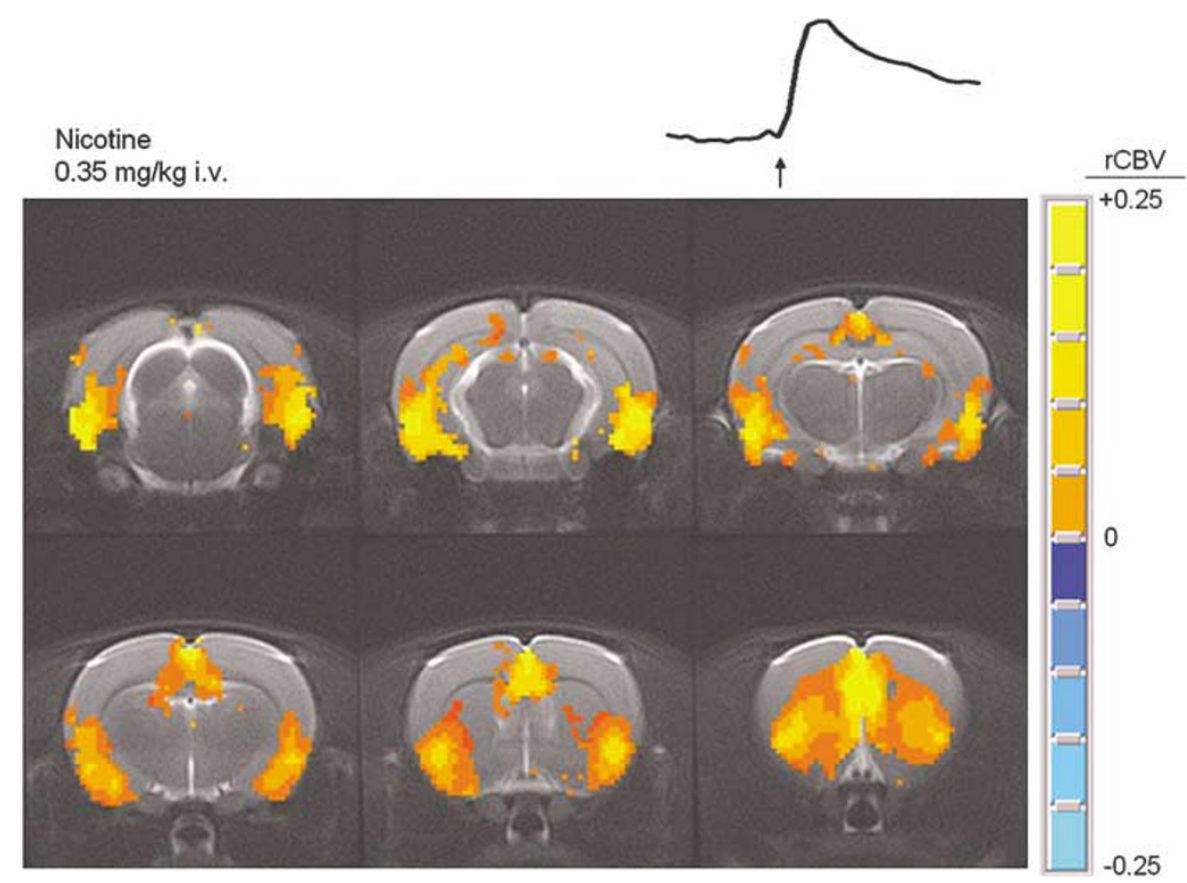

Figure 2 Maps of rCBV response following acute nicotine challenge $(0.35 \mathrm{mg} / \mathrm{kg}$ i.v.; $n=9)$ relative to vehicle $(n=7)$ and thresholded at a false discovery rate of $1 \%(q=0.01)$. The color scale indicates the magnitude of the fractional $r C B V$ change. The temporal profile of the regressor used as a signal model in the GLM analysis (see Materials and methods) is shown at the top right of the activation map, with an arrow indicating the time of injection. (Two additional caudal slices covering structures of the hindbrain and the cerebellum were analyzed but did not show significant activation, and are therefore not reported here.) 

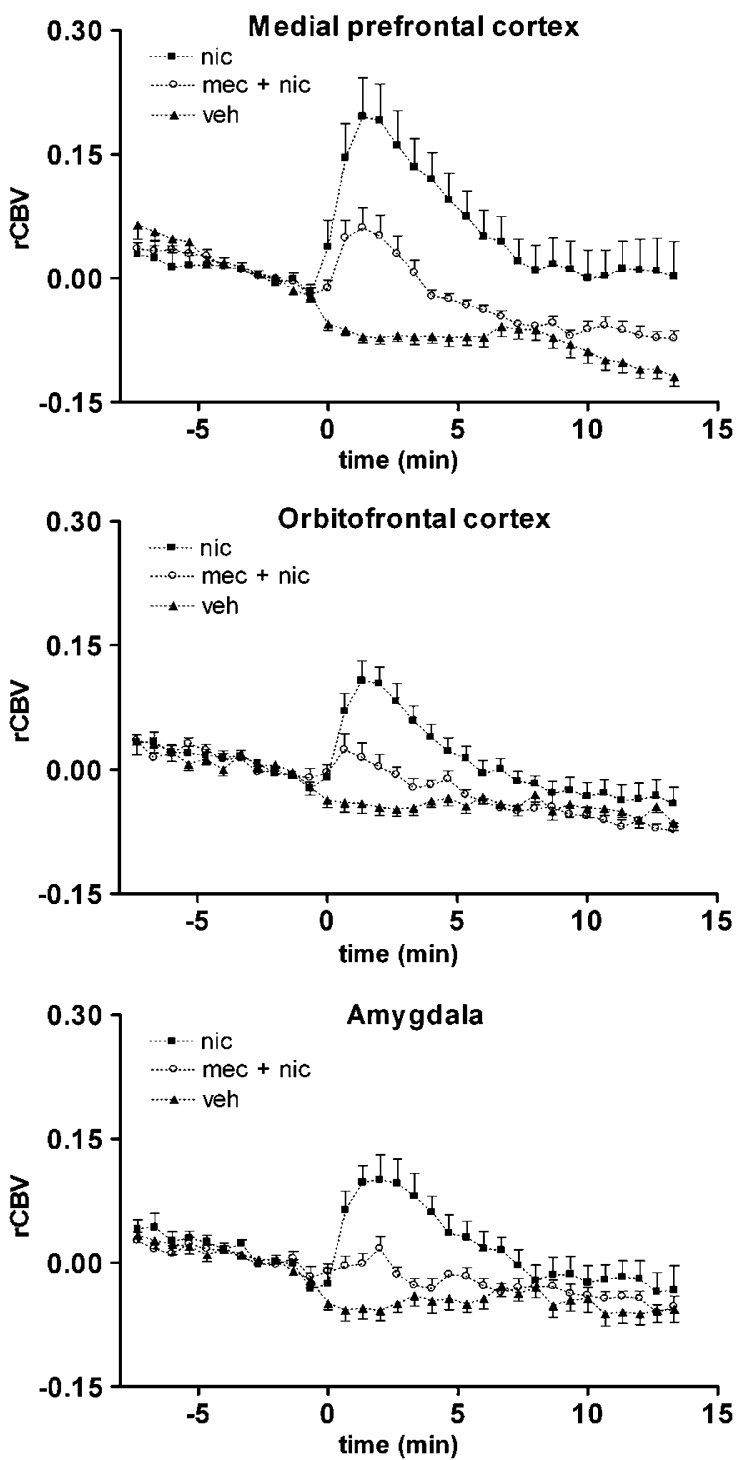

Figure $3 \mathrm{ROI}$ time courses showing rCBV changes following nicotine challenge with and without pretreatment with mecamylamine, in three representative regions (nic: rats pretreated with vehicle and challenged with nicotine $0.35 \mathrm{mg} / \mathrm{kg}$ i.v. $(n=9) ; \quad \mathrm{mec}+$ nic: pretreatment with mecamylamine ( $\mathrm{mg} / \mathrm{kg}$ i.p., $n=7$ ) followed by a nicotine challenge $0.35 \mathrm{mg} / \mathrm{kg}$ i.v.; veh: control rats challenged and pretreated with vehicle $(n=4))$. Data are plotted as mean \pm SEM within each group.

nicotine $(0.1 \mathrm{mg} / \mathrm{kg})$ did not produce detectable cardiovascular changes. 5IA induced a fast-onset increase in arterial blood pressure $(+25.8 \pm 2.1 \%, p<0.05$ at peak compared to vehicle) very similar in shape and duration to the one previously observed with nicotine (Figure 9). Administration of MEC was accompanied by a slow and progressive decrease in blood pressure, which reached a stable negative plateau ca. $20 \mathrm{~min}$ after injection $(-20.3 \pm 4.6 \%, p<0.01$ compared to predrug baseline). The effect persisted for more than $30 \mathrm{~min}$ and was still present at the time of the nicotine challenge. CpdA produced a dose-dependent decrease in MBP, which reached a minimum approximately $1 \mathrm{~min}$ after the start of the injection (Figure 9). At the two highest doses the magnitudes of the effect were similar $(-34.5 \pm 12.8$ and $-36.4 \pm 5.4 \%$ at 30 and $20 \mathrm{mg} \mathrm{kg}$, respectively), but at $30 \mathrm{mg} / \mathrm{kg}$ the effect was slightly more

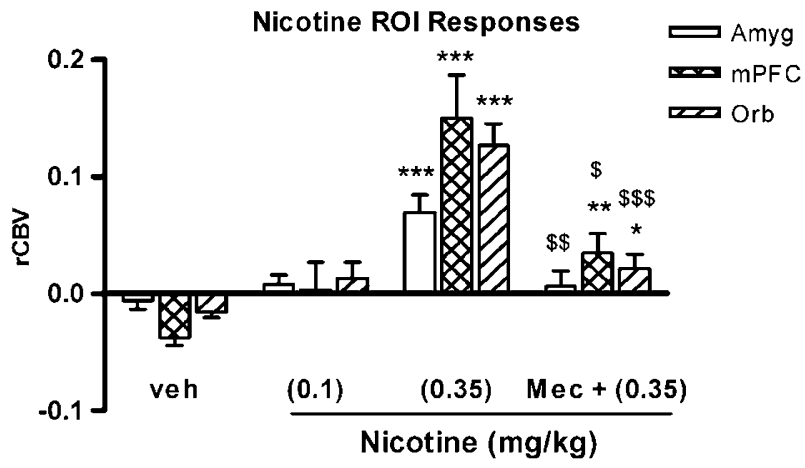

Figure 4 Effect of pretreatment with mecamylamine (I mg/kg i.p., $n=7)$ on the rCBV response induced by acute nicotine challenge $(0.1$ and $0.35 \mathrm{mg} / \mathrm{kg}$ i.v., $n=7$ and 9, respectively) in three representative anatomical regions (Amy, amygdala; mPFC, medial prefrontal cortex; Orb, orbitofrontal cortex). Baseline data of control animals who received a saline injection are reported for comparison $(n=9)$. Data are expressed as mean + SEM within each group. veh: control rats challenged with vehicle; $\mathrm{Mec}+$ 0.35: nicotine challenge $(0.35 \mathrm{mg} / \mathrm{kg}$ i.v. $)$ following pretreatment with mecamylamine (I mg/kg i.p.). $* p<0.05$ vs vehicle, $* * * 0.01$ vs vehicle, ${ }^{*} * * * 0.001$ vs vehicle, ${ }^{\$} p<0.05$ vs vehicle pretreated nicotine challenge $(0.35),{ }^{\$ \$} p<0.01$ vs vehicle pretreated nicotine challenge $(0.35)$ $\$ \$ \$<0.00$ I vehicle pretreated nicotine challenge $(0.35)$.

sustained. At 10 and $3 \mathrm{mg} / \mathrm{kg}$, the changes were not statistically different from vehicle $(p>0.112$ and 0.217 , respectively, all time-points). The absolute magnitude of the blood pressure changes observed with nicotine, 5IA, and cpdA (at all doses) was within the range of CBF autoregulation $(50-140 \mathrm{mmHg}$ ) under halothane anesthesia reported by Zaharchuk et al (1999).

In the acute norepinephrine challenge study, a blood pressure increase similar in amplitude and shape to that elicited by nicotine was observed $(+32.7 \pm 17.0 \%, p<0.05$ at peak compared to vehicle; Figure 8). PhMRI group activation maps of norepinephrine $v s$ vehicle did not reveal significant $\mathrm{rCBV}$ changes in any brain region. Similarly, a post hoc ROI analysis in nine brain structures (see Figure 1) did not evidence significant alterations in the CBV baseline attributable to the norepinephrine challenge. These results suggest that the observed functional changes are centrally mediated and not caused by the transient peripheral increase in MBP, in line with previous studies, which showed that MBP changes within the cerebral blood flow autoregulatory range do not cause significant changes in CBV (Zaharchuk et al, 1999).

\section{DISCUSSION}

The preclinical investigation of the acute effects of nicotine is often based on experimental methods that require ex vivo approaches or focal measurements of brain activity. This has limited the possibility of obtaining a comprehensive picture of nicotine's neuromodulatory activity within the brain. As a consequence, little is known of nicotine's acute effects on neuronal activity at a systems level. Functional MRI techniques allow noninvasive three-dimensional brain mapping of the functional response induced by various types of stimulus, including pharmacologically active agents. Animal phMRI research represents a promising tool for the identification and optimization of experimental 


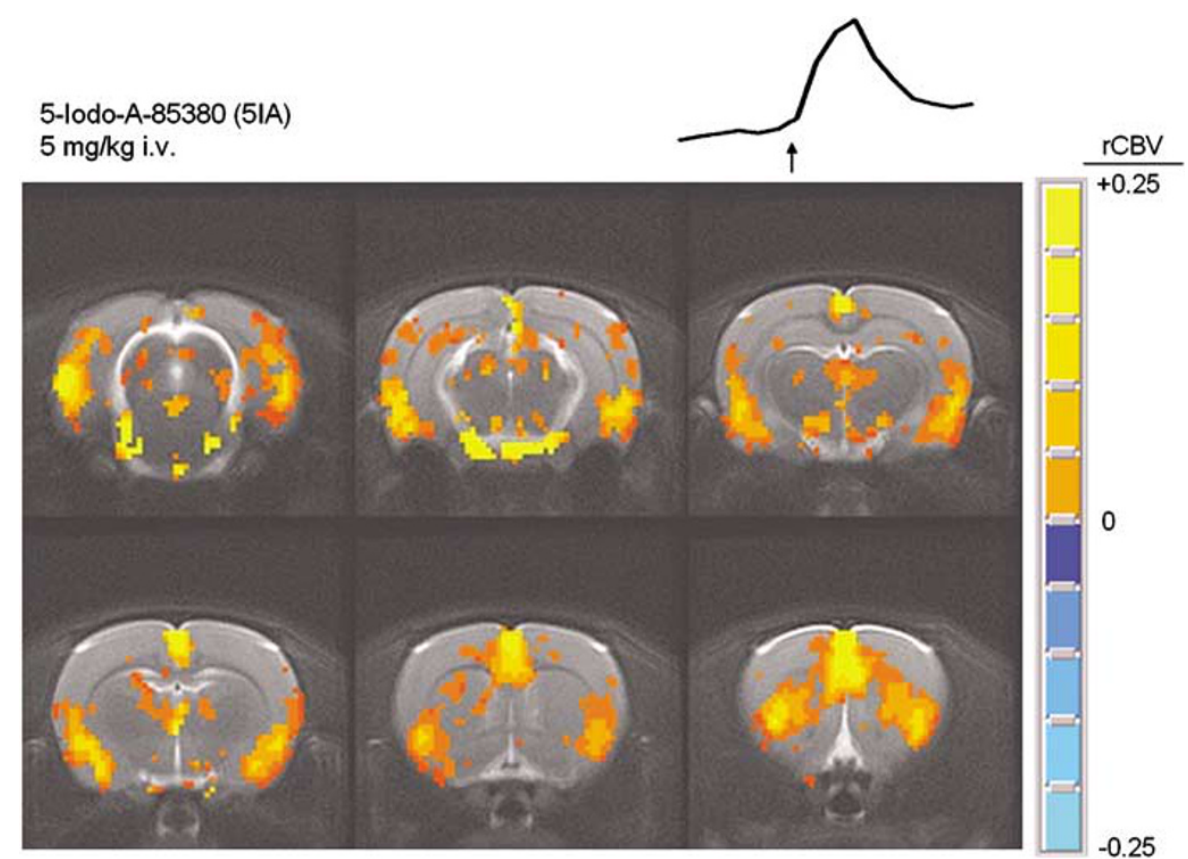

Figure 5 Maps of the rCBV response following acute $5 \mathrm{IA}$ challenge $(5 \mathrm{mg} / \mathrm{kg}$ i.v., $n=6)$, relative to vehicle $(n=5)$ and thresholded at a false discovery rate of $\mid \%(q=0.01)$. The color scale indicates the magnitude of the fractional rCB $\vee$ change. The temporal profile of the regressor used as a signal model in the GLM analysis (see Materials and methods) is shown at the top right of the activation map, with an arrow indicating the time of injection. (Two additional caudal slices covering structures of the hindbrain and the cerebellum were analyzed but did not show significant activation, and are therefore not reported here.)

paradigms aimed at determining a drug's mechanism and site of action. CBV-sensitive phMRI methods have a high sensitivity at $4.7 \mathrm{~T}$ magnetic fields (Mandeville et al, 1998), and have been recently applied to map pharmacologically evoked activation elicited by several neuroactive substances in rodents (Chen et al, 1997; Nguyen et al, 2000; Marota et al, 2000; Reese et al, 2000; Schwarz et al, 2004a, b; Gozzi et al, 2005b).

In the present study, we have applied phMRI methods to map for the first time the acute rCBV response to nicotine in drug-naïve rats. Several lines of evidence argue strongly that the changes in $\mathrm{rCBV}$ described here are a direct consequence of nicotine-induced regional increase in neuronal activity and not due to unspecific peripheral effects of nicotine or a global effect on cerebral vasculature. Firstly, the pattern of activation observed with both nicotine and 5IA is region-specific, with CBV remaining unchanged in a number of brain regions. The significant attenuation of activation by the nAChR antagonist mecamylamine also supports the pharmacological specificity of the process. Furthermore, by reproducing the blood pressure response to nicotine with a systemic infusion of norepinephrine, a potent vasopressor that does not cross the blood-brain barrier (Tuor et al, 2002), no detectable rCBV changes were detected centrally, thus corroborating the idea that the observed rCBV response is not the predominant result of peripheral vascular changes. Moreover, the magnitude of the blood pressure changes elicited by nicotine and 5IA was within the range of central hemodynamic autoregulation described by Zaharchuk et al (1999). These authors have shown that, under an anesthetic protocol very similar to the one used in our study, CBF autoregulation is preserved over a wide range a values (from 50 to $140 \mathrm{mmHg}$ ), and that changes in blood pressure within this range produce only small and nonsignificant changes in rCBV. Finally, previous studies have shown that perivascular microapplication of nicotine on the cortical surface exerted negligible effects on pial vessels over a wide range of concentrations, consistent with the local increase in rCBV occurring as a result of increased metabolic demand and nicotine having either no or only a minor direct influence on the cerebral circulation (Edvinsson and Krause, 2002). In conclusion, converging evidence strongly supports the hypothesis that the pattern of brain activation we observed is a direct consequence of the selective action of nicotine on particular cortical and subcortical targets resulting in neural activation within specific structures. As 5IA closely reproduced the activation pattern and cardiovascular changes elicited by nicotine, and since it is known to stimulate the same receptors as nicotine, it is reasonable to assume that the observed $\mathrm{rCBV}$ changes are also the result of central activity of 5IA on specific neuronal populations in the brain.

I.v. infusion of nicotine elicited region-specific increase in rCBV in several cortical (medial-prefrontal, cingulate, orbital, piriform, frontal and rhinal cortices) and subcortical (amygdala, caudal-ventral hippocampal structures) structures. All the brain regions identified in this study have been reported to have moderate to high density of nAChR subunit mRNA and nicotine-binding sites (Clarke et al, 1985; Wada et al, 1989; Tribollet et al, 2004). The anatomical pattern of the functional response comprises many structures that have previously been identified with different brain-mapping modalities to be acutely modulated by nicotine. Mathieu-Kia et al (1998) reported a c-Fos-like pattern strikingly similar to the activation maps reported in this study, with increased Fos immunoreactivity in terminal 

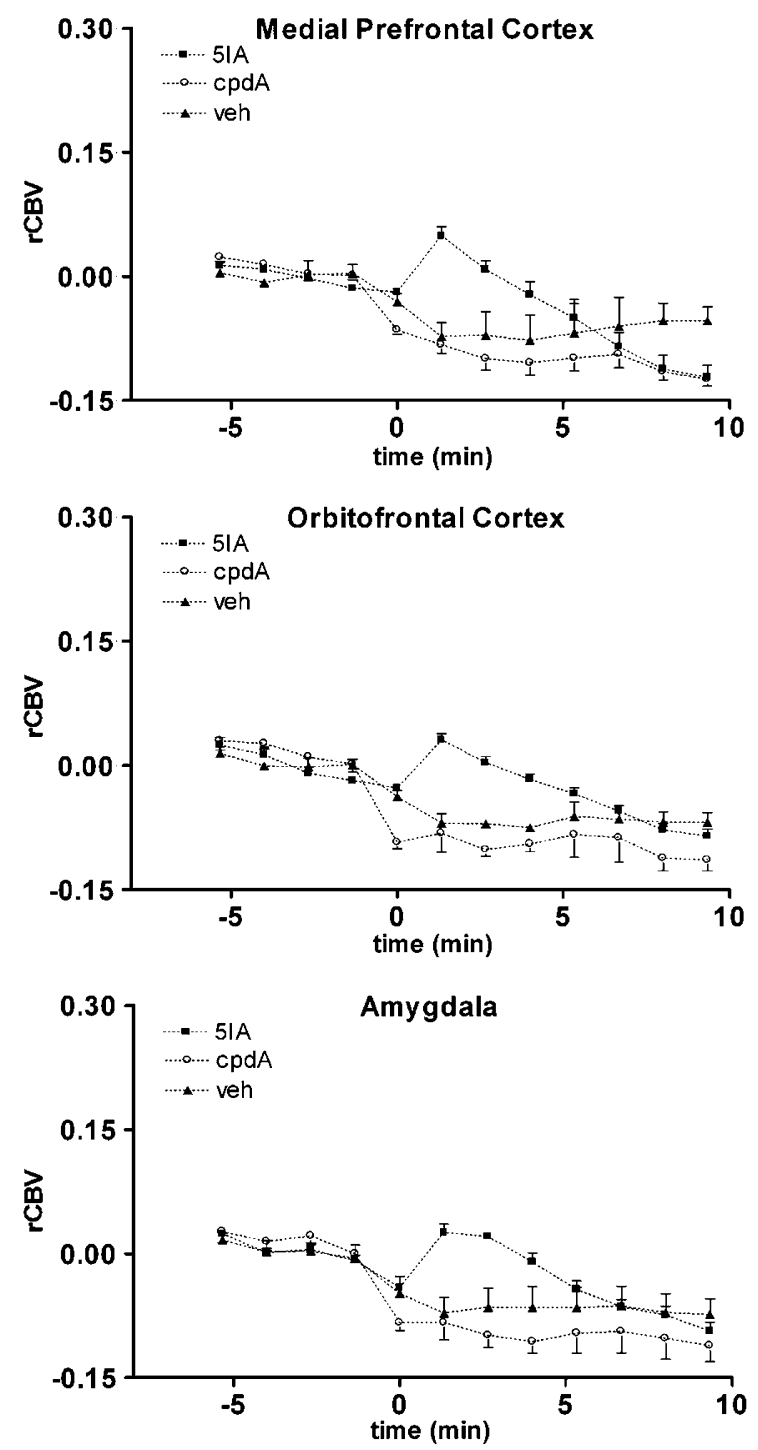

Figure $6 \mathrm{ROI}$ time courses showing rCBV changes following acute 5IA challenge $(5 \mathrm{mg} / \mathrm{kg}$ iv, $n=6)$, cpdA (30 mg/kg i.v., $n=4)$, or vehicle (saline i.v., $n=5)$ in three representative anatomical regions. Data are plotted as mean \pm SEM within each group.

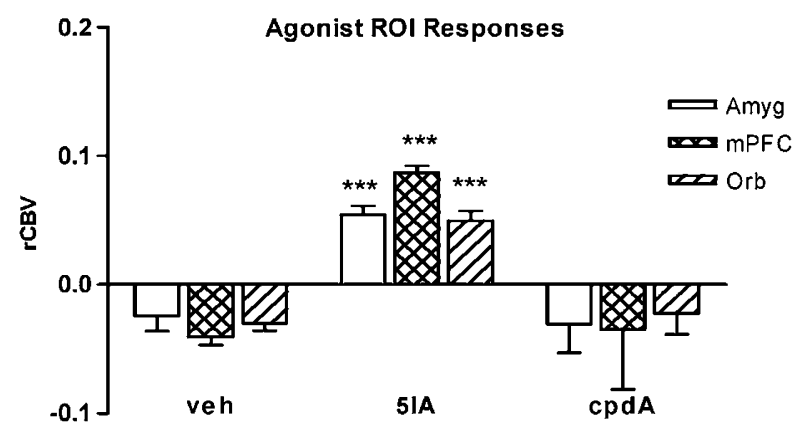

Figure $7 \quad R C B V$ response to acute challenge with $5 \mathrm{IA}(5 \mathrm{mg} / \mathrm{kg}$ i.v., $n=6)$ and cpdA (20 mg/kg i.v., $n=5)$ in three representative anatomical regions (Amy, amygdala; mPFC, medial prefrontal cortex; Orb, orbitofrontal cortex). Baseline data of control animals who received a saline injection are reported for comparison $(n=5)$. Data are expressed as mean \pm SEM within each group. $* * * * 0<0.001$ vs vehicle.

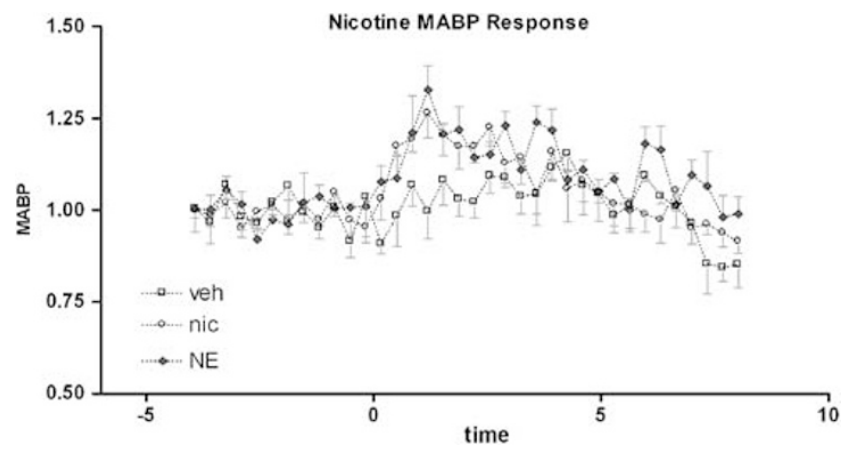

Figure 8 Effect of nicotine $(0.35 \mathrm{mg} / \mathrm{kg}, n=9)$, norepinephrine $(0.5 \mu \mathrm{g} /$ $\mathrm{kg}, n=4$ ), and vehicle (saline, $n=9$ ) infusion on the time course of MABP (relative changes). Data are shown as mean \pm SEM across subjects for each time point.

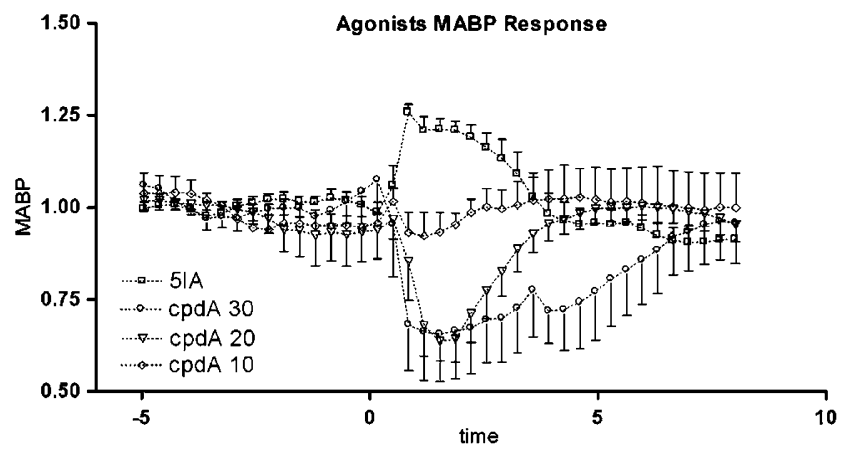

Figure 9 Effect of $5 \mathrm{IA}(5 \mathrm{mg} / \mathrm{kg}, \mathrm{n}=5)$ and $\mathrm{cpd} A(10,20$, and $30 \mathrm{mg} / \mathrm{kg}$, $n=4,5$, and 4 , respectively) infusion on the time course of MABP (relative changes). The effect of control (saline) injection has already been reported in Figure 8, and has not been plotted here to improve the clarity of the figure. Data are shown as mean \pm SEM across subjects for each time point.

fields of neurons of the ventral tegmental area, such as the $\mathrm{mPFC}$ and the central amygdala, as well as in the cingulate, orbital, and piriform cortices. Increased c-fos immunoreactivity in these structures was also reported by other investigators (Matta et al, 1993; Kiba and Jayaraman, 1994; Schilstrom et al, 2000; Seppa et al, 2001). The present study also seems to indicate a preferential involvement of cortical structures with a rich dopamine innervation (medial prefrontal, cingulate, orbital, pirirform) compared with those (frontal and parietal) with fewer dopaminergic terminals. This finding is in close agreement with the results of previous studies with c-fos immunodetection (Mathieu-Kia et al, 1998; Schilstrom et al, 2000; Seppa et al, 2001). Using autoradiographic 2-deoxy-D- $\left[1-{ }^{14} \mathrm{C}\right]$ glucose methods, many cortical areas were analyzed and only the cingulate cortex (Grunwald et al, 1991) showed an increased local cerebral glucose utilization. Hyder et al (2000) recorded an increase in $\mathrm{CBF}$ in the somatosensory cortex of rats challenged with a high dose of nicotine $(4 \mathrm{mg} / \mathrm{kg})$. Of particular interest is the activation found in the rhinal cortex, since this area, together with the prefrontal and orbitrofrontal cortices and the hippocampus, serves as a key neuroanatomical substrate of recognition memory in rats (Steckler et al, 1998). The involvement of brain structures that mediate recognition memory is consistent with the results of behavioral studies that show improved working 
memory functions following acute treatment with nicotine in drug-naïve rats (reviewed by Levin and Simon, 1998).

Increasing evidence suggest a modulation of mesolimbic and mesocortical dopamine pathways by acute nicotine administration (Kiba and Jayaraman, 1994; Laviolette and Van der Kooy, 2004). Functional c-fos studies reported preferential activation in structures that receive dopaminergic afferents from the VTA, such as the nucleus accumbens and the central amygdala, but not in the dorsal caudate-putamen innervated by projections from the substantia nigra pars compacta (Mathieu-Kia et al, 1998). Consistent with this, we observed positive activation in the $\mathrm{mPFC}$ and the central amygdala. A clear signal enhancement was also found in the anterior portion of the nucleus accumbens. However, the response is not uniform across the structure, and appears to be weaker in its posterior segments. As the most anterior portion of the nucleus accumbens borders on strongly activated areas such as the orbital cortex, a signal contamination from the highly responsive neighboring structures cannot be excluded. The data presented here therefore do not establish unequivocally whether the nucleus accumbens is activated by acute nicotine under our experimental conditions, and the answer to this question must await further experiments. The presence of activation in the $\mathrm{MPFC}$, the amygdala, and nucleus accumbens would be indicative of a preferential nicotine interaction with dopaminergic neurons of the ventral tegmental area as reported by Mathieu-Kia et al (1998), although a presynaptic action of nicotine on dopaminergic terminals or a direct nicotine activation of neurons in the activated structure cannot be excluded.

Notably, although previous $c$-fos and local cerebral glucose utilization studies (London et al, 1988a, b; Grunwald et al, 1991) reported increased immunoreactivity in visual and limbic structures connected with the retina, none of these structures seem to be functionally activated in our rCBV activation maps. As the superior collicoli are involved in the representation of visual, auditory, and somatosensory stimuli (Sparks, 1986; Guitton, 1992), the lack of activation in central visual pathways may be attributed to the absence of multimodal sensorimotor information, a general consequence of the direct general suppressive effects of the anesthetics on neural transmission (Franks and Lieb, 1998; Angel, 1993). This hypothesis is corroborated by the results of Wang et al (2000), who reported an anesthesia-induced suppression of c-Fos immunoreactivity induced by noxious stimuli in different layers of the superior colliculus.

Previous functional studies using $c$-fos immunodetection or the deoxyglucose method also highlighted the acute effects of nicotine also in nAChR-dense areas that were not identified in the present study, such as the dorsolateral striatum (Kiba and Jayaraman, 1994; Nisell et al, 1997), various catechoalminergic regions of the brainstem (Matta et al, 1993), and thalamic and hypothalamic structures (London et al, 1988a; Mathieu-Kia et al, 1998; Seppa et al, 2001). An increase in thalamic areas was also revealed by measuring the local cerebral blood flow rats (Grunwald et al, 1991). Although differences in the dose and route of administration of nicotine exist, these discrepancies could be due to the use of the anesthetic. Our phMRI protocol includes the use of general anesthesia to avoid motion artifacts and ensure stable and reproducible animal physiology. Halothane is an anesthetic widely used in preclinical phMRI, as it has been shown to preserve cerebrovascular reactivity and cerebral blood flow autoregulatory response (Morita et al, 1977; Young et al, 1991; Lee et al, 1994). However, halothane, like most general anesthetics, exert, its activity through simultaneous interactions with some nAChR-dense neuronal structures, including the thalamus, midbrain reticular formation, and the hypothalamus (for a review, see Rudolph and Antkowiak, 2004). Also, several volatile and injectable anesthetics have been reported to inhibit in vitro various nAChRs subtypes at concentrations that might be clinically relevant (Violet et al, 1997). Therefore, complex in vivo interactions between the anesthetic and the nicotinic receptors can in principle affect the extent or distribution of the rCBV response. Nonetheless, the distribution of the rCBV changes observed in this work is congruous, reproducible, and consistent with several previously published results, thus suggesting that, if these interactions do occur, they only marginally affect the functional response to nicotinic agonists.

By using mecamylamine, a nonselective nAChR antagonist that is thought to block the nicotinic ion channels (Giniatullin et al, 2000), we were able to demonstrate the involvement of nAChRs in the observed functional response. This result is in agreement with in vivo studies in nonanesthetized animals, in which blockade of nAChRs by preadministration of mecamylamine has been shown to antagonize the behavioral and neurometabolic effects of nicotine (London et al, 1988a; Ren and Sagar, 1992; Pang et al, 1993; Kiba and Jayaraman, 1994; Marshall et al, 1997). In subsequent experiments, we sought to assess the relative contribution of different receptor subtypes to the response to nicotine by using selective $\mathrm{nAChR}$ agonists. Understanding the differential contribution of the diverse nAChR isoforms represents an important opportunity to develop drugs that selectively retain the cognition-enhancing properties of nicotine, while minimizing the unwanted side-effects (eg, hypothermia, nausea, cardiovascular changes, and abuse liability). The majority of the pharmacological tools available target the two most abundant nAChRs subtypes in the brain: $\alpha 7$ and $\alpha 4 \beta 2^{\star}$. These two receptor isoforms have both shown to be implicated in the functions of learning and memory and the cognitiveenhancing properties of nicotine (Rezvani and Levin, 2001; Levin et al, 2002). Recent results suggest that both receptors are implicated in the behavioral modulation of the reinforcing properties of nicotine, although with distinct roles (Wonnacott et al, 2005). Several behavioral and pharmacological studies of nicotinic receptor subtype take advantage of the availability of potent and selective nAChR antagonists such as methyllcaconitine (Ward et al, 1990) and dihydro-beta-erythroidine (Williams and Robinson, 1984). However, both compounds are competitive antagonists, and MLA has been reported to have a poor brain penetration and it is often administered directly into the brain to bypass the blood-brain barrier (Wonnacott and Sharples, 2001; Navarro et al, 2002; Van Kampen et al, 2004). The fact that these drugs interact reversibly with the nAChR channel, along with the poor PK profile of MLA, may compromise studies like the present one in which the infusion of a high-dose bolus of nicotinic agonists 
(eg nicotine) is required to produce detectable signal changes. Unsurprisingly, attempts to antagonize nicotine's response by using the aforementioned drugs failed to give consistent results (Gozzi A, unpublished results). To overcome these shortcomings, here we have applied a different approach and used two novel compounds that show selective agonist activity at $\alpha 7$ and $\alpha 4 \beta 2$ receptors, respectively.

CpdA is a potent $\left(\mathrm{EC}_{50}=14 \mathrm{nM}\right)$ and centrally penetrant nAChR agonist with nearly full efficacy at human $\alpha 7$ receptors expressed in GH4 cells. This compound shows negligible activity at other major $\mathrm{nAChR}$ subtypes $(\alpha 2 \beta 4$, $\alpha 3 \beta 4, \alpha 4 \beta 4, \alpha 3 \beta 2$, and $\alpha 4 \beta 2)$ and is devoid of $5-\mathrm{HT}_{3}$ activity (De Filippi et al, 2002; O'Neill et al, 2002; Bunnelle and Decker, 2003). In this study, the evaluation of cpdA as a single challenge at four increasing doses failed to induce significant $\mathrm{rCBV}$ changes at any of the doses tested. In previous reports, cpdA (1-10 mg/kg i.p.) showed rapid and robust in vivo central effects as assessed by behavioral (Wadsworth et al, 2005; Cilia et al, 2005) and neurochemical studies (Tong and Dawson, 2005). Therefore, the absence of significant $\mathrm{rCBV}$ changes following cpdA administration is unlikely to be the result of low potency or poor CNS penetration. The magnitude of the negative blood pressure changes in rats treated with high doses $(20$ and $30 \mathrm{mg} / \mathrm{kg}$ ) of cpdA were within the autoregulatory range identified by Zaharchuk et al (1999). Moreover, cpdA did not produce significant activation at any of the lower doses, including 5 and $10 \mathrm{mg} / \mathrm{kg}$, at which cpdA induces robust behavioral effects (Wadsworth et al, 2005; Cilia et al, 2005), without significantly affecting the blood pressure. Therefore, peripheral effects are unlikely to have precluded detection of centrally mediated response to the compound. A further potential issue is the rapid desensitization that is characteristic of agonist-mediated responses at the $\alpha 7$ receptor (Seguela et al, 1993; Quick and Lester, 2002). Given that any exogenously administered drug will be present in the extracellular space of the receptor for a time period of minutes to hours, the $\alpha 7$ receptor may be in a predominantly desensitized state. CpdA, like other selective $\alpha 7$ agonists, induces rapid receptor desensitization in vitro, and probably in vivo (O'Neill et al, 2002). However, nicotine at the dose tested in this study reaches brain concentration levels that are substantially above the submicromolar range needed for effective $\alpha 7$ desensitization (Ghosheh et al, 2001; Quick and Lester, 2002). It is therefore conceivable that $\alpha 7$ receptors are also in a desensitized state following nicotine administration. Based on these considerations, it can be assumed that there was no substantial difference between the maximum steady-state currents induced by nicotine and cpdA. As discussed above, the anesthetic is another experimental factor that, in principle, could interfere with the neurometabolic cascade underlying the $\mathrm{rCBV}$ response. However, $\alpha 7$ nicotinic receptors do not appear to be significantly inhibited by clinically relevant concentrations of halothane (Violet et al, 1997; Tassonyi et al, 2002). Taken together, these data suggest that a failure of cpdA to elicit significant $\mathrm{rCBV}$ changes is unlikely to be due to explanations such as stronger receptor desensitization or unfavorable interactions with the anesthetic. Since cpdA did not produce a significant response at any of the doses tested, we therefore conclude that the selective pharmacological stimulation of $\alpha 7$ nicotinic receptors is not accompanied by hemodynamic changes. As nicotine showed a robust neurovascular response, this finding suggests that the $\mathrm{rCBV}$ response to nicotine is not predominantly mediated by $\alpha 7$ nAChRs.

The evaluation of 5IA revealed a pattern of activation showing a striking spatial correspondence with the distribution of nicotine-induced CBV changes. Functional activation was found in all the cortical and subcortical structures previously described for nicotine. Interestingly, 5IA also elicited focal activation in regions of the dorsomedial thalamus and in the hypothalamic areas. The presence of activation in these nuclei is in good agreement with the very high and uniform density of high-affinity $\alpha 4 \beta 2^{*}$ nicotinic receptor in the thalamus (Clarke et al, 1985). Several experimental factors can contribute to the detection of significant thalamic activation in 5IA but not in nicotine rCBV maps, and a direct comparison of the pharmacological potency of these two compounds in vivo is beyond the scope of this paper. As brain-concentration levels of 5IA following i.v. administration are not available in the literature, no conclusions can be drawn on the relative extra synaptic concentrations of the two compounds under the experimental conditions of this study. However, a higher in vivo potency with respect to nicotine would be compatible with the pharmacological profile of 5IA, as demonstrated by competitive binding studies in which 5IA showed seven-fold higher affinity than nicotine at $\alpha 4 \beta 2^{*}$ receptors (Saji et al, 2002).

In vitro, 5IA features exceptional selectivity for the $\alpha 4 \beta 2^{*}$ subtype when compared to $\alpha 7, \alpha 3 \beta 4^{\star}$, and muscle type nAChRs (Mukhin et al, 2000). Recent results have shown that 5IA is also a potent activator of $\alpha 6 \beta 2^{*}$ receptors in vitro (Mogg et al, 2002), and based on this finding it is now generally referred to as $\beta 2^{*}$-selective nicotinic receptor ligand (Liu et al, 2003). Thanks to its high-affinity, low nonspecific binding, and lack of toxicity in mammals, 5IA has been characterized as a tool for noninvasive in vivo studies of $\beta 2^{*}$ nicotinic receptor (Vaupel et al, 1998, 2005). Since the affinity of 5IA toward $\alpha 7 \mathrm{nAChRs}$ is only $1 / 25000$ of that towards $\alpha 4 \beta 2$, it is reasonable to assume that the compound has negligible activity at $\alpha 7$ receptor in vivo, and that any residual activity at $\alpha 7$ receptors would be largely outweighed by the predominant action at $\beta 2^{*}$ receptors. In line with this, $\beta 2$-knockout mice showed total loss of 5IA binding in all brain regions of Mukhin et al (2000). Taken together, these data suggest that the $\mathrm{rCBV}$ changes produced by 5IA are mediated by $\beta 2^{*} \mathrm{nAChRs}$. Considering the lack of phMRI response to cpdA, and the high spatial overlap between the activation profile of nicotine and 5IA, this also suggests that the functional response to nicotine is predominantly mediated by $\beta 2^{*} \mathrm{nAChRs}$. Consequently, in addition to having a crucial role in mediating some key aspect of the addictive and acute cognitive properties of nicotine (Levin, 2002; Picciotto, 2003; Kauer, 2005), $\beta 2$ containing nAChRs appear to be also implicated in the modulation of the acute hemodynamic response to nicotine. Considering that 5IA shows significant potency only for $\alpha 4 \beta 2^{*}$ and $\alpha 6 \beta 2^{*}$, and that the most abundant $\beta 2$-containing receptors in mammalian brain are $\alpha 4 \beta 2^{*}$ (Flores et al, 1992), it is likely that the major specific signal produced by 5IA and nicotine would reflect a response mediated by $\alpha 4 \beta 2^{*}$ nAChRs. In line with this hypothesis, $\alpha 6 \beta 2^{*}$ nAChRs 
are present in low concentration and show limited distribution in the brain (Picciotto et al, 2001), with a focal localization at dopaminergic terminals, such as the medial habenula, the locus coruleus, and the substantia nigra pars compacta, that did not show activation in this study.

To the best of our knowledge, no functional neuroimaging study on the acute effects of nicotine in drug-naïve individuals has been published to date. MRI methods have been used to investigate aspects of the neuroplastic changes induced by repeated nicotine exposure nicotine in two recent rodent studies (Shoaib et al, 2004; Calderan et al, 2005). Clinical studies using positron emission tomography and fMRI in smokers, or abstinent smokers, have also been published (reviewed by McClernon and Gilbert, 2004). However, repeated exposure to nicotine induces complex and long-lasting changes in the biochemistry of the brain, including a substantial upregulation of nicotinic-binding sites (Benwell et al, 1988; Buisson and Bertrand, 2002). Moreover, neuroimaging studies in abstinent individuals do not allow an easy separation of the acute effects of the drug from the functional correlates of craving (Hommer, 1999). Taken together, these aspects limit the possibility of a direct comparison between the findings of this study and the results of previously published neuroimaging studies. In this respect, the data presented here represent a novel and valuable preclinical benchmark for future clinical investigations of the functional effects of selective nicotinic agents by using fMRI methods.

In conclusion, we have applied phMRI methods to map the functional response to nicotine in drug-naïve rats. Nicotine produced a distinct and reproducible pattern of activation including cortical and subcortical structures involved in the mediation of the acute cognitive and behavioral effects of nicotine. The pharmacological specificity of the effect was demonstrated by acute pretreatment with the nAChR ion-channel-blocking agent mecamylamine, which suppressed the rCBV response to nicotine. After acute challenge with a selective CNS penetrant $\alpha 7$ nAChR agonist, we did not observe a detectable CBV response, while experiments with a selective $\beta 2^{*} \mathrm{nAChR}$ agonist elicited a pattern of activation very similar to that of nicotine. Taken together, these results suggest that the hemodynamic response to nicotine in drug-naïve individuals is predominantly mediated by $\beta 2$-containing $\mathrm{nAChR}$ isoforms presumably belonging to the $\alpha 4 \beta 2^{*}$ subtype. As nicotinic agents possess well-established cognitive-enhancing properties, the results of this study may help the identification of the neuronal substrates mediating aspects of cognitive and attentional functions.

\section{ACKNOWLEDGEMENTS}

We are grateful to James Kew for critical reading of the manuscript, and to Emma Maskell, of Ion Channel Chemistry, GlaxoSmithKline, Stevenage, for the synthesis of cpdA.

\section{REFERENCES}

Alyautdin RN, Tezikov EB, Ramge P, Kharkevich DA, Begley DJ, Kreuter J (1998). Significant entry of tubocurarine into the brain of rats by adsorption to polysorbate 80 -coated polybutylcyanoacrylate nanoparticles: an in situ brain perfusion study. $J$ Microencapsul 15: 67-74.

Angel A (1993). Central neuronal pathways and the process of anaesthesia. Br J Anaesth 71: 148-163.

Benwell ME, Balfour DJ, Anderson JM (1988). Evidence that tobacco smoking increases the density of $(-)-\left[{ }^{3} \mathrm{H}\right]$ nicotine binding sites in human brain. J Neurochem 50: 1243-1247.

Buisson B, Bertrand D (2002). Nicotine addiction: the possible role of functional upregulation. Trends Pharmacol Sci 23: 130-136.

Bunnelle WH, Decker MW (2003). Neuronal nicotinic acetylcholine receptor ligands as potential analgesics. Expert Opin Ther Patents 13: 1003-1021.

Calderan L, Chiamulera C, Marzola P, Fabene PF, Fumagalli GF, Sbarbati A (2005). Sub-chronic nicotine-induced changes in regional cerebral blood volume and transversal relaxation time patterns in the rat: a magnetic resonance study. Neurosci Lett 377: 195-199.

Chen YC, Galpern WR, Brownell AL, Matthews RT, Bogdanov M, Isacson O et al (1997). Detection of dopaminergic neurotransmitter activity using pharmacologic MRI: correlation with PET, microdialysis, and behavioral data. Magn Reson Med 38: 389-398.

Chiodini FC, Tassonyi E, Hulo S, Bertrand D, Muller D (1999). Modulation of synaptic transmission by nicotine and nicotinic antagonists in hippocampus. Brain Res Bull 48: 623-628.

Cilia J, Cluderay JE, Robbins MJ, Reavill C, Southam E, Kew JN et al (2005). Reversal of isolation-rearing-induced PPI deficits by an alpha7 nicotinic receptor agonist. Psychopharmacology (Berl) 182: 214-219.

Clarke PB, Schwartz RD, Paul SM, Pert CB, Pert A (1985). Nicotinic binding in rat brain: autoradiographic comparison of [3H]acetylcholine, [3H]nicotine, and [125I]-alpha-bungarotoxin. J Neurosci 5: 1307-1315.

Corrigall WA (1991). Understanding brain mechanisms in nicotine reinforcement. Br J Addict 86: 507-510.

Cox RW, Hyde JS (1997). Software tools for analysis and visualization of FMRI Data. NMR Biomed 10: 171-178.

Dani JA, Heinemann S (1996). Molecular and cellular aspects of nicotine abuse. Neuron 16: 905-908.

De Filippi G, Broad LM, Zwart R, Baldwinson T, Felthouse C, McPhie G et al (2002). Pharmacological Characterisation and In Vitro physiological Effects of New 7 Nicotinic Acetylcholine Receptor Agonists, Vol 137. Society for Neuroscience (Online): Washington, DC, p 1.

Edvinsson L, Krause DN (2002). Cerebral Blood Flow and Metabolism. Lippincott Williams \& Wilkins: Philadelphia.

Flores CM, Rogers SW, Pabreza LA, Wolfe BB, Kellar KJ (1992). A subtype of nicotinic cholinergic receptor in rat brain is composed of alpha 4 and beta 2 subunits and is up-regulated by chronic nicotine treatment. Mol Pharmacol 41: 31-37.

Franks NP, Lieb WR (1998). Which molecular targets are most relevant to general anaesthesia? Toxicol Lett 100-101: 1-8.

Genovese CR, Lazar NA, Nichols T (2002). Thresholding of statistical maps in functional neuroimaging using the false discovery rate. NeuroImage 15: 870-878.

Ghosheh OA, Dwoskin LP, Miller DK, Crooks PA (2001). Accumulation of nicotine and its metabolites in rat brain after intermittent or continuous peripheral administration of [2'-14C]nicotine. Drug Metab Dispos 29: 645-651.

Giniatullin RA, Sokolova EM, Di Angelantonio S, Skorinkin A, Talantova MV, Nistri A (2000). Rapid relief of block by mecamylamine of neuronal nicotinic acetylcholine receptors of rat chromaffin cells in vitro: an electrophysiological and modeling study. Mol Pharmacol 58: 778-787.

Gotti C, Fornasari D, Clementi F (1997). Human neuronal nicotinic receptors. Prog Neurobiol 53: 199-237. 
Gozzi A, Schwarz A, Reese T, Bertani S, Crestan V, Bifone A (2005a). Functional imaging of nicotine and selective nicotinic acetylcholine receptor agonists in the anesthetised rat. Second UK Nicotinic Receptor Club Meeting, Vol P-2, Harlow, UK, p 19.

Gozzi A, Schwarz AJ, Reese T, Bertani S, Bifone A (2005c). Functional imaging of nicotine in the anaesthetised rat. Book of abstracts: 13th Annual Meeting of the International Society of Magnetic Resonance in Medicine, Vol P-1508. Miami, p 307.

Gozzi A, Schwarz AJ, Reese T, Crestan V, Bertani S, Turrini G et al (2005b). Functional magnetic resonance mapping of intracerebroventricular infusion of a neuroactive peptide in the anaesthetised rat. J Neurosci Methods 142: 115-124.

Grunwald F, Schrock H, Kuschinsky W (1987). The effect of an acute nicotine infusion on the local cerebral glucose utilization of the awake rat. Brain Res 400: 232-238.

Grunwald F, Schrock H, Kuschinsky W (1991). The influence of nicotine on local cerebral blood flow in rats. Neurosci Lett 124: $108-110$.

Guitton D (1992). Control of eye-head coordination during orienting gaze shifts. Trends Neurosci 15: 174-179.

Holladay MW, Dart MJ, Lynch JK (1997). Neuronal nicotinic acetylcholine receptors as targets for drug discovery. J Med Chem 40: 4169-4194.

Hommer DW (1999). Functional imaging of craving. Alcohol Res Health 23: 187-196.

Hyder F, Kennan RP, Kida I, Mason GF, Behar KL, Rothman D (2000). Dependence of oxygen delivery on blood flow in rat brain: a 7 tesla nuclear magnetic resonance study. J Cereb Blood Flow Metab 20: 485-498.

Itier V, Bertrand D (2001). Neuronal nicotinic receptors: from protein structure to function. FEBS Lett 504: 118-125.

Jenkins BG, Chen Y-CI, Mandeville JB (2003). Pharmacological magnetic resonance imaging (phMRI). In: van Bruggen $\mathrm{N}$, Roberts T (eds). Biomedical Imaging in Experimental Neuroscience. CRC Press: New York. pp 155-209.

Kauer JA (2005). Neuroscience: a home for the nicotine habit. Nature 436: 31-32.

Kiba H, Jayaraman A (1994). Nicotine induced c-fos expression in the striatum is mediated mostly by dopamine D1 receptor and is dependent on NMDA stimulation. Brain Res Mol Brain Res 23: $1-13$.

Kuryatov A, Olale F, Cooper J, Choi C, Lindstrom J (2000). Human [alpha]6 AChR subtypes: subunit composition, assembly, and pharmacological responses. Neuropharmacology 39: 25702590.

Laviolette SR, Van der Kooy D (2004). The neurobiology of nicotine addiction: bridging the gap from molecules to behaviour. Nat Rev Neurosci 5: 55-65.

Le Novere N, Zoli M, Lena C, Ferrari R, Picciotto MR, Merlo-Pich E et al (1999). Involvement of alpha6 nicotinic receptor subunit in nicotine-elicited locomotion, demonstrated by in vivo antisense oligonucleotide infusion. NeuroReport 10: 2497-2501.

Lee JG, Hudetz AG, Smith JJ, Hillard CJ, Bosnjak ZJ, Kampine JP (1994). The effects of halothane and isoflurane on cerebrocortical microcirculation and autoregulation as assessed by laserdoppler flowmetry. Anesthesia Analgesia 79: 58-65.

Levin ED (2002). Nicotinic receptor subtypes and cognitive function. J Neurobiol 53: 633-640.

Levin ED, Bradley A, Addy N, Sigurani N (2002). Hippocampal alpha 7 and alpha 4 beta 2 nicotinic receptors and working memory. Neuroscience 109: 757-765.

Levin ED, Rezvani AH (2002). Nicotinic treatment for cognitive dysfunction. Curr Drug Targets CNS Neurol Disord 1: 423-431.

Levin ED, Simon BB (1998). Nicotinic acetylcholine involvement in cognitive function in animals. Psychopharmacology (Berl) 138: 217-230.

Liu X, Koren AO, Yee SK, Pechnick RN, Poland RE, London ED (2003). Self-administration of 5-iodo-A-85380, a beta2-selective nicotinic receptor ligand, by operantly trained rats. NeuroReport 14: $1503-1505$.

London ED, Connolly RJ, Szikszay M, Wamsley JK, Dam M (1988a). Effects of nicotine on local cerebral glucose utilization in the rat. J Neurosci 8: 3920-3928.

London ED, Dam M, Fanelli RJ (1988b). Nicotine enhances cerebral glucose utilization in central components of the rat visual system. Brain Res Bull 20: 381-385.

London ED, Fanelli RJ, Kimes AS, Moses RL (1990). Effects of chronic nicotine on cerebral glucose utilization in the rat. Brain Res 520: 208-214.

Lukas RJ, Changeux JP, le Novere N, Albuquerque EX, Balfour DJ, Berg DK et al (1999). International Union of Pharmacology. XX. Current Status of the Nomenclature for Nicotinic Acetylcholine Receptors and Their Subunits. Pharmacol Rev 51: 397-401.

Mandeville JB, Marota JJA, Kosofsky BE, Keltner JR, Weissleder R, Rosen B et al (1998). Dynamic functional imaging of relative cerebral blood volume during rat forepaw stimulation. Magn Reson Med 39: 615-624.

Marota JJA, Mandeville JB, Weisskoff R, Moskowitz MA, Rosen B, Kosofsky BE (2000). Cocaine activation discriminates dopaminergic projections by temporal response: an fMRI study in rat. NeuroImage 11: 13-23.

Marshall DL, Redfern PH, Wonnacott S (1997). Presynaptic nicotinic modulation of dopamine release in the three ascending pathways studied by in vivo microdialysis: comparison of naive and chronic nicotine-treated rats. J Neurochem 68: 1511-1519.

Mathieu-Kia AM, Pages C, Besson MJ (1998). Inducibility of c-Fos protein in visuo-motor system and limbic structures after acute and repeated administration of nicotine in the rat. Synapse 29: 343-354.

Matta SG, Foster CA, Sharp BM (1993). Nicotine stimulates the expression of cFos protein in the parvocellular paraventricular nucleus and brainstem catecholaminergic regions. Endocrinology 132: 2149-2156.

McClernon FJ, Gilbert J (2004). Human functional neuroimaging in nicotine and tobacco research: basics, background, and beyond. Nicotine Tobacco Res 6: 941-959.

McGehee DS, Role LW (1995). Physiological diversity of nicotinic acetylcholine receptors expressed by vertebrate neurons. Annu Rev Physiol 57: 521-546.

Mogg AJ, Jones FA, Pullar IA, Sharples CGV, Wonnacott S (2004). Functional responses and subunit composition of presynaptic nicotinic receptor subtypes explored using the novel agonist 5-iodo-A-85380. Neuropharmacology 47: 848-859.

Mogg AJ, Whiteaker P, McIntosh JM, Marks M, Collins AC, Wonnacott S (2002). Methyllycaconitine is a potent antagonist of alpha-conotoxin-MII-sensitive presynaptic nicotinic acetylcholine receptors in rat striatum. J Pharmacol Exp Ther 302: 197-204.

Morita H, Nemoto EM, Bleyaert AL, Stezoski SW (1977). Brain blood flow autoregulation and metabolism during halothane anesthesia in monkeys. Am J Physiol 2: H670-H676.

Mukhin AG, Gundisch D, Horti AG, Koren AO, Tamagnan G, Kimes AS et al (2000). 5-Iodo-A-85380, an alpha 4beta 2 subtype-selective ligand for nicotinic acetylcholine receptors. Mol Pharmacol 57: 642-649.

Navarro HA, Xu H, Zhong D, Abraham P, Carroll FI (2002). In vitro and in vivo characterization of [125I] iodomethyllycaconitine in the rat. Synapse 44: 117-123.

Nguyen TV, Brownell A-L, Chen Y-CI, Livni E, Coyle JT, Rosen B et al (2000). Detection of the effects of dopamine receptor supersensitivity using pharmacological MRI and correlations with PET. Synapse 36: 57-65.

Nisell M, Nomikos GG, Chergui K, Grillner P, Svensson TH (1997). Chronic nicotine enhances basal and nicotine-induced Fos immunoreactivity preferentially in the medial prefrontal cortex of the rat. Neuropsychopharmacology 17: 151-161. 
Ogawa S, Menon RS, Tank DW, Kim SG, Merkle H, Ellermann JM et al (1993). Functional brain mapping by blood oxygenation level-dependent contrast magnetic resonance imaging. A comparison of signal characteristics with a biophysical model. Biophys J 64: 803-812.

Oldendorf WH (1971). Brain uptake of radiolabeled amino acids, amines, and hexoses after arterial injection. Am J Physiol 221: $1629-1639$

O’Neill MJ, Moore NA, McKinzie DL, Keenan M, Wishart G, Shannon HE et al (2002). Behavioural profiling of two potent alpha 7 nicotinic acetylcholine receptor agonists, Vol 137. Society for Neuroscience (Online): Washington DC, p 1.

Pang Y, Kiba H, Jayaraman A (1993). Acute nicotine injections induce c-fos mostly in non-dopaminergic neurons of the midbrain of the rat. Brain Res Mol Brain Res 20: 162-170.

Papke RL, Sanberg PR, Shytle RD (2001). Analysis of mecamylamine stereoisomers on human nicotinic receptor subtypes. J Pharmacol Exp Ther 297: 646-656.

Paterson D, Nordberg A (2000). Neuronal nicotinic receptors in the human brain. Prog Neurobiol 61: 75-111.

Paxinos G, Watson C (1998). The Rat Brain in Stereotactic Coordinates. Academic Press: San Diego.

Picciotto MR (2003). Nicotine as a modulator of behavior: beyond the inverted U. Trends Pharmacol Sci 24: 493-499.

Picciotto MR, Caldarone BJ, Brunzell DH, Zachariou V, Stevens TR, King SL (2001). Neuronal nicotinic acetylcholine receptor subunit knockout mice: physiological and behavioral phenotypes and possible clinical implications. Pharmacol Ther 92: 89-108.

Quick MW, Lester RA (2002). Desensitization of neuronal nicotinic receptors. J Neurobiol 53: 457-478.

Reavill C, Stolerman IP (1990). Locomotor activity in rats after administration of nicotinic agonists intracerebrally. $\mathrm{Br} J$ Pharmacol 99: 273-278.

Reese T, Bjelke B, Porszasz R, Baumann D, Bochelen D, Sauter A et al (2000). Regional brain activation by bicuculline visualized by functional magnetic resonance imaging. time-resolved assessment of bicuculline-induced changes in local cerebral blood volume using an intravascular contrast agent. NMR Biomed 13: 43-49.

Ren T, Sagar SM (1992). Induction of c-fos immunostaining in the rat brain after the systemic administration of nicotine. Brain Res Bull 29: 589-597.

Rezvani AH, Levin ED (2001). Cognitive effects of nicotine. Biol Psychiatry 49: 258-267.

Romanelli MN, Gualtieri F (2003). Cholinergic nicotinic receptors: competitive ligands, allosteric modulators, and their potential applications. Med Res Rev 23: 393-426.

Rudolph U, Antkowiak B (2004). Molecular and neuronal substrates for general anaesthetics. Nat Rev Neurosci 5: 709-720.

Saji H, Ogawa M, Ueda M, Iida Y, Magata Y, Tominaga A et al (2002). Evaluation of radioiodinated 5-iodo-3-(2(S)azetidinylmethoxy)pyridine as a ligand for SPECT investigations of brain nicotinic acetylcholine receptors. Ann Nucl Med 16: 189-200.

Schilstrom B, De Villiers S, Malmerfelt A, Svensson TH, Nomikos GG (2000). Nicotine-induced Fos expression in the nucleus accumbens and the medial prefrontal cortex of the rat: role of nicotinic and NMDA receptors in the ventral tegmental area. Synapse 36: 314-321.

Schilstrom B, Rawal N, Mameli-Engvall M, Nomikos GG, Svensson TH (2003). Dual effects of nicotine on dopamine neurons mediated by different nicotinic receptor subtypes. Int $J$ Neuropsychopharmacol 6: 1-11.

Schwarz A, Gozzi A, Reese T, Bertani S, Crestan V, Hagan J et al (2004a). Selective dopamine $\mathrm{D}(3)$ receptor antagonist SB277011-A potentiates phMRI response to acute amphetamine challenge in the rat brain. Synapse 54: 1-10.
Schwarz A, Whitcher B, Reese T, Gozzi A, Bifone A (2005). Grouplevel data-driven phMRI analysis. Book of Abstracts: Thirteenth Annual Meeting of the International Society of Magnetic Resonance in Medicine, Vol 13. Miami, p 157.

Schwarz AJ, Reese T, Gozzi A, Bifone A (2003). Functional MRI using intravascular contrast agents: detrending of the relative cerebrovascular (rCBV) time course. Magn Reson Imaging 21: $1191-1200$

Schwarz AJ, Zocchi A, Reese T, Gozzi A, Garzotti M, Varnier G et al (2004b). Concurrent pharmacological MRI and in situ microdialysis of cocaine reveal a complex relationship between the central hemodynamic response and local dopamine concentration. Neuroimage 23: 296-304.

Seguela P, Wadiche J, Dineley-Miller K, Dani JA, Patrick JW (1993). Molecular cloning, functional properties, and distribution of rat brain alpha 7: a nicotinic cation channel highly permeable to calcium. J Neurosci 13: 596-604.

Seppa T, Salminen O, Moed M, Ahtee L (2001). Induction of Fosimmunostaining by nicotine and nicotinic receptor antagonists in rat brain. Neuropharmacology 41: 486-495.

Shoaib M, Lowe AS, Williams SC (2004). Imaging localised dynamic changes in the nucleus accumbens following nicotine withdrawal in rats. Neuroimage 22: 847-854.

Sparks DL (1986). Translation of sensory signals into commands for control of saccadic eye movements: role of primate superior colliculus. Physiol Rev 66: 118-171.

Steckler T, Drinkenburg WHIM, Sahgal A, Aggleton JP (1998). Recognition memory in rats-II. Neuroanatomical substrates. Neurobiol 54: 313-332.

Tassonyi E, Charpantier E, Muller D, Dumont L, Bertrand D (2002). The role of nicotinic acetylcholine receptors in the mechanisms of anesthesia. Brain Res Bull 57: 133-150.

Tong X, Dawson LA (2005). Effects of an alpha7 receptor agonist on forebrain neurochemistry: a microdialysis study. Second UK Nicotinic Receptor Club Meeting, Vol P-32, Harlow, UK, p 49.

Tribollet E, Bertrand D, Marguerat A, Raggenbass M (2004). Comparative distribution of nicotinic receptor subtypes during development, adulthood and aging: an autoradiographic study in the rat brain. Neuroscience 124: 405-420.

Tuor UI, McKenzie E, Tomanek B (2002). Functional magnetic resonance imaging of tonic pain and vasopressor effects in rats. Magn Reson Imaging 20: 707-712.

Van Kampen M, Selbach K, Schneider R, Schiegel E, Boess F, Schreiber R (2004). AR-R 17779 improves social recognition in rats by activation of nicotinic alpha7 receptors. Psychopharmacology (Berl) 172: 375-383.

Vaupel DB, Mukhin AG, Kimes AS, Horti AG, Koren AO, London ED (1998). In vivo studies with [125I]5-I-A-85380, a nicotinic acetylcholine receptor radioligand. NeuroReport 9: 2311-2317.

Vaupel DB, Tella SR, Huso DL, Mukhin AG, Baum I, Wagner WO et al (2005). Pharmacology, toxicology and radiation dosimetry evaluation of [123I]5-I-A-85380, a radioligand for in vivo imaging of cerebral neuronal nicotinic acetylcholine receptors in humans. Drug Dev Res 58: 149-168.

Violet JM, Downie DL, Nakisa RC, Lieb WR, Franks NP (1997). Differential sensitivities of mammalian neuronal and muscle nicotinic acetylcholine receptors to general anesthetics. Anesthesiology 86: 866-874.

Wada E, Wada K, Boulter J, Deneris E, Heinemann S, Patrick J et al (1989). Distribution of alpha 2, alpha 3, alpha 4, and beta 2 neuronal nicotinic receptor subunit mRNAs in the central nervous system: a hybridization histochemical study in the rat. $J$ Comp Neurol 284: 314-335.

Wadsworth G, Stean T, Stratton S, Upton N (2005). Behavioural consequences of mecamylamine in rats: a model of alpha7 nicotinic acetylcholine receptor function. Second UK Nicotinic Receptor Club Meeting, Vol P-31, Harlow, UK, p 48. 
Wang S, Wang H, Niemi-Junkola U, Westby GW, McHaffie JG, Stein BE et al (2000). Parallel analyses of nociceptive neurones in rat superior colliculus by using c-fos immunohistochemistry and electrophysiology under different conditions of anaesthesia. J Comp Neurol 425: 599-615.

Ward JM, Cockcroft VB, Lunt GG, Smillie FS, Wonnacott S (1990). Methyllycaconitine: a selective probe for neuronal alphabungarotoxin binding sites. FEBS Lett 270: 45-48.

Weisskoff RM, Zuo CS, Boxerman JL, Rosen BR (1994). Microscopic susceptibility variation and transverse relaxation: theory and experiment. Magn Reson Med 31: 601-610.

Whitcher B, Schwarz AJ, Barjat H, Smart SC, Grundy RI, James MF (2005). Wavelet-based cluster analysis: data-driven grouping of voxel time courses with application to perfusion-weighted and pharmacological MRI of the rat brain. Neuroimage 24: 281-295.
Williams M, Robinson JL (1984). Binding of the nicotinic cholinergic antagonist, dihydro-beta-erythroidine, to rat brain tissue. J Neurosci 4: 2906-2911.

Wonnacott S, Sharples CG (2001). Neruonal nicotinic receptors. Tocris Rev 19: 1-12.

Wonnacott S, Sidhpura N, Balfour DJ (2005). Nicotine: from molecular mechanisms to behaviour. Curr Opin Pharmacol 5: 53-59.

Young WL, Barkai AI, Prohovnik I, Nelson H, Durkin M (1991). Effect of $\mathrm{PaCO} 2$ on cerebral blood flow distribution during halothane compared with isoflurane anaesthesia in the rat. $\mathrm{Br} J$ Anaesth 67: 440-446.

Zaharchuk G, Mandeville JB, Bogdanov Jr AA, Weissleder R, Rosen BR, Marota JJ (1999). Cerebrovascular dynamics of autoregulation and hypoperfusion. An MRI study of CBF and changes in total and microvascular cerebral blood volume during hemorrhagic hypotension. Stroke 30: 2197-2204. 